
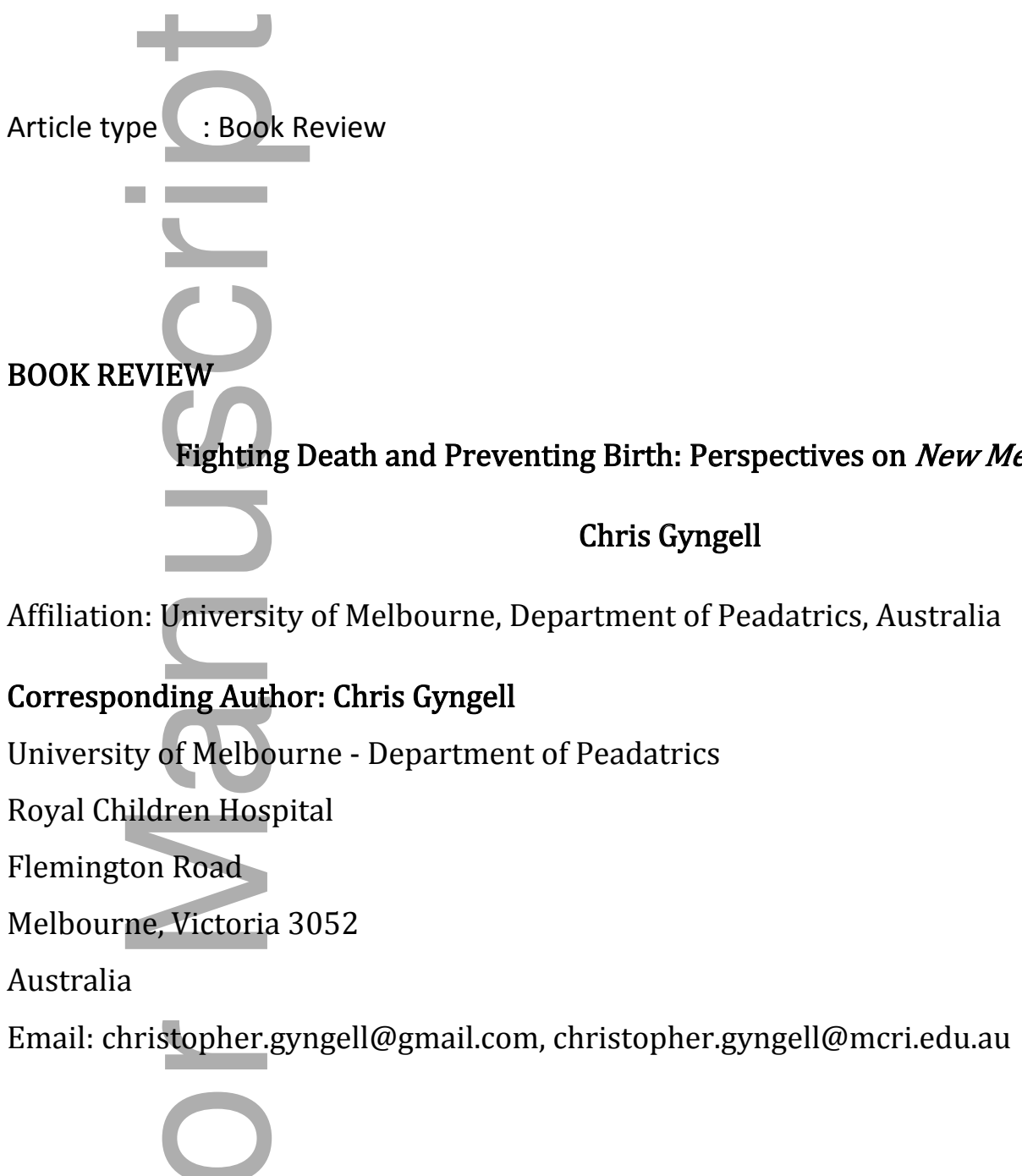

Christopher Gyngell is a Research Fellow in Biomedical Ethics at the Murdoch Children's Research Institute; Lecturer in the Department of Paediatrics at the University of Melbourne; and a Senior Research Fellow at the Melbourne Law School. His research interests lie primarily in the ethical implications of biotechnologies and the philosophy of health and disease.

The quest to extend our lives is starting to attract significant investment, particularly from Silicon Valley. Google co-founder Larry Page has launched a biotech company called Calico,

This is the author manuscript accepted for publication and has undergone full peer review but has not been through the copyediting, typesetting, pagination and proofreading process, which may lead to differences between this version and the Version of Record. Please cite this article as doi: 10.1111/BIOE.12623

This article is protected by copyright. All rights reserved 
which aims to extend the human lifespan, and has over 1.5 billion in capital. Oracle co-founder Larry Ellison has given more than $\$ 430$ million toward anti-ageing research.

With this amount of investment, and with rapid advances in stem cell technologies, genomics, gene editing, and artificial intelligence; it would be bold to claim there wouldn't be an extension of the human lifespan sometime soon. It is thus important to consider the ethical implications of altering human ageing.

In his book, New Methuselahs: The ethics of life extension ${ }^{1}$, John K Davis provides an excellent overview of the ethics of living longer. Though the topic of life extension has been of interest to philosophers for centuries, it has been off the radar in the last few years. Given the renewed interest in the science of ageing, it is time for a fresh analysis of the ethical implications of life extension.

New Methuselahs provides both a thorough summary of previous work on the ethics of life extension and makes several novel contributions to the field. The central vibe is that there is nothing intrinsically bad about life-extension; that it could do a lot of good, and that the practical challenges it presents could be met. Davis thinks we should encourage research into life extension, and that we have obligations to provide life extension technologies to those who desire them. It is an optimistic take on the issue, but one driven by consideration of the issues rather than an ideological commitment.

In this brief review, I will first provide some general comments on the book as a whole; note the books most novel contributions to the literature; before discussing what I see as the account's biggest weakness.

\section{Overall comments}

The first thing to say about New Methuselahs is that it is a great example of practical ethics. The discussion is anchored by a desire to help inform practical and policy decisions. It thus only considers philosophical arguments that have relevance to plausible life extension scenarios leaving aside more theoretical arguments about immortality. Drawing on work from demographers, Davis draws an upper limit on the degree of life extension that would be possible to achieve, at 1000 years (p20). This is because, even if we stopped ageing completely (which some gerontologists believe is biologically possible), deaths due to accidents, infectious disease, etc., would keep average life expectancies to 1000 years (although some could, in theory, live much longer than this).

\footnotetext{
${ }^{1}$ J.K. Davis. New Methuselahs: the ethics of life extension. Cambridge, MA: MIT Press.
} 
Davis structures his argument in a novel way. He considers a future society with access to life extension, and divides the population into three groups: Those that have access to life extension technologies and use it (The Haves); those that have access to life extension technology and do not use it (The Will-nots); and those do not have access to life extension technologies (The Have-nots).

In this first half of the book, Davis introduces concerns that relate to each of these groups. For example, the claim that life-extension will lead to terrible boredom (Chapter 2) is a concern for the Haves; the concern that it will increase inequalities (Chapter 8) a concern for the Have-nots; and the claim that rejecting life-extension is an equivalent to suicide (Chapter 4), is relevant to The Will-nots.

The structure of these chapters is relevantly similar. In each case, Davis introduces a concern about life-extension; distinguishes its scope and implications; and then critically assesses it. For most objections to life extension; Davis shows they are either conceptually problematic or only have limited scope and implications. A lot of the arguments presented here are not highly original, but Davis presents them with admirable clarity.

The second half of the book focusses more on how we should weigh the interest of competing groups (The Have's, Have-nots, and The Will-nots). Davis argues that concerns for The Will-nots and The Have-not's do not justify limiting access to The Haves. Even if only some can access life extension technologies; and thus its provision will exacerbate injustices, this does not justify prohibiting access, or inhibiting research. However, The Haves should expect to be taxed to help subsidy access to The Have-Nots (p156).

\section{The Malthusian Threat}

The most important and novel part of the book is the in-depth look at the Malthusian objection to life extension - a problem Davis has examined in previously published work. ${ }^{2}$ The Malthusian objection holds that we have moral reasons to abstain from life extension as it will lead to overpopulation and exacerbate several environmental and social problems. Unlike previous concerns considered by Davis that only applied to either the Haves, Have-nots, or Willnots, this objection applies to all.

A major achievement of this section is to put some numbers behind this previously undeveloped objection (Chapter 6). Davis works with demographer Shahin Davoudpour, to model the effects on population size of different life extension scenarios. Some of the results are shocking. What sounds like relatively moderate increases in life expectancy, can lead to huge jumps in

\footnotetext{
2 J.K. Davis. Life-extension and the Malthusian Objection. J Med Philos 2005; 30(1): 27-44: 27-44.
} 
population size. Davis and Davoudpour model scenarios in which a billion of the world's population increase their life expectancy to 150, and reproduce at replacement levels (a birth rate of 2.0). This would quickly increase the global population by 2 billion. A relatively small increase in life expectancy has huge effects on population size.

Just as surprising is that much more radical increases in life expectancy yield similar demographic impacts. Increasing the life expectancy of a billion people to 1000 (assuming a birth rate of 2); would increase the global population by 3 billion. This is interesting because, intuitively, technologies that can increase life expectancy to 1000 raise very different ethical challenges than ones that raise life expectancy to 150. Davis shows, counter-intuitively, the overall effects on population size are relatively similar.

Such radical population increases could lead to widespread social and environmental damage due to overpopulation. The prospect of overpopulation is clearly a valid reason to be wary of widespread life-extending interventions.

Davis recognises this. His solution is to adopt a "forced choice policy", where essentially people have to choose between having children and extending their lives (Davis policy is more complex than this, involving lotteries to reproduce). Such an encompassing policy requires a big state to enforce it. Davis envisions governments that enforce mandatory genetic testing, and keep databases of everyone's genetic information so that they can monitor who has had children. I think there are problems with this solution. Obviously many would find such a state undesirable both for reasons of privacy and for the potential for misuse. Davis recognises and responds to some of these concerns. However, an aspect of forced choice that is not considered is the flow on effects of dramatically reducing the rate of generational turnover.

\section{Preventing births}

An intuitive worry about radical life-extension is stagnation. Each new generation introduces new people, new genes, and new ideas. If radical life extension reduced the rate at which new people are introduced into society, it could reduce the influx of novel ideas.

Davis considers the objection that life extension will lead to a reduction in the rate of innovation and social change in Chapter 5 . However, some of his responses are uncharacteristically flippant. For example

"It's true that young people tend to be the agents of social change and more open to novel approaches and ideas. Creative and innovative industries tend to be led by people in their 
20 's and 30's. Of course, we might be pleasantly surprised. We might find that there is still enough innovation and social change going on " (p96)

And

"It's also possible to overestimate the value of innovation and social change...although rapid innovation is exciting for some people, many find it very stressful" (p97)

Such statements demonstrate a lack of engagement with the work of scholars (me); who have appealed to evolutionary processes to support claims that radical life extension would have a negative effect on innovation. ${ }^{3}$

In brief, reducing the rate of generation turnover (a likely effect of "forced choice")is likely to reduce the generation of novel cultural variants. The ideas that individuals are first exposed to help determine how they interpret and respond to subsequent information. This is reflected in the psychological phenomena 'belief-dependent realism'. Once individuals have a set of beliefs, they become invested in them, and this limits their ability to acquire other beliefs. A constant generational turnover ensures that naive minds are constantly developing in unique cultural environments and are exposed to different cultural variants early in development. This means that, over time, populations have a large number of different individuals exist in them, each of whom is disposed to develop different cultural variants. If radical life extension slows the rate of generational turnover, it may reduce the variance in ideas and skills that are available to populations over time. This could be harmful to many human endeavours which effect well-being such as the Arts and Sciences and could make the species less adaptable and more susceptible to existential risks.

This is not to say that such reason provides a knockdown case against life extension, or Davis's forced choice policy solution. But they need to be considered in such discussions. In a world with "forced choice", how would music be affected? How would science be affected? How would our ability to solve problems like climate change be affected? These are important questions that deserve serious analysis, but which are absent from New Methuselahs.

This is a relatively minor criticism of what otherwise is a good book. New Methuselah provides a great investigation into the ethics of life extension. It provides bold, thought-provoking policy suggestions, which will no doubt stimulate future work on the topic. Anyone with an interest in life extension and ethics should read it.

\footnotetext{
${ }^{3}$ C. Gyngell. The Ethics of Human Life Extension: The Second Argument from Evolution. J Med Philos 2015; 40(6): 696-713: 696-713.
}

This article is protected by copyright. All rights reserved 


\section{University Library}

\section{- M M I E E R VA A gateway to Melbourne's research publications}

Minerva Access is the Institutional Repository of The University of Melbourne

Author/s:

Gyngell, C

Title:

FIGHTING DEATH AND PREVENTING BIRTH: PERSPECTIVES ON NEW METHUSELAHS

Date:

2019-09-01

Citation:

Gyngell, C. (2019). FIGHTING DEATH AND PREVENTING BIRTH: PERSPECTIVES ON NEW METHUSELAHS. BIOETHICS, 33 (7), pp.849-850. https://doi.org/10.1111/bioe.12623.

Persistent Link:

http://hdl.handle.net/11343/286880 